\section{Intersections}

Canadian Journal of Music

Revue canadienne de musique
Intersections CANADIAN JOURAL OF MUSIC
REVUE CANADIENEE DE MUSIOUH

\title{
Performance Strategies in Three Recordings of Bach's Invention No. 1 in C Major: A Comparative Study
}

\section{Alan Dodson}

Volume 31, numéro 2, 2011

URI : https://id.erudit.org/iderudit/1013213ar

DOI : https://doi.org/10.7202/1013213ar

Aller au sommaire du numéro

\section{Éditeur(s)}

Canadian University Music Society / Société de musique des universités canadiennes

ISSN

1911-0146 (imprimé)

1918-512X (numérique)

Découvrir la revue

Citer cet article

Dodson, A. (2011). Performance Strategies in Three Recordings of Bach's Invention No. 1 in C Major: A Comparative Study. Intersections, 31(2), 43-64. https://doi.org/10.7202/1013213ar
Résumé de l'article

Après une brève introduction au domaine des études d'interprétation empirique et à ses objectifs, l'auteur traite d'enregistrements de l'oeuvre mentionnée dans le titre par les pianistes Harold Bauer, Glenn Gould et Angela Hewitt. Il soutient que ces enregistrements témoignent de trois stratégies d'interprétation distinctes de l'oeuvre : Bauer fait ressortir les limites de chaque phrase et projette une conception téléologique au sein de celle-ci et à l'échelle de l'oeuvre dans son ensemble, Gould adopte une conception en forme d'arche liée à la tension harmonique, tandis que Hewitt attire l'attention non seulement sur les trois cadences structurelles (aux $7^{\mathrm{e}}, 15^{\mathrm{e}}$ et $22^{\mathrm{e}}$ measure), mais aussi à un mouvement subsidiaire V-I à la 11 measure, faisant ainsi allusion à son importance structurelle possible. L'auteur établit brièvement des parallèles entre ces stratégies d'interprétation et des analyses de Howard Cinnamon, de Steve Larson et de Roy Travis. L'accent sur la multiplicité distingue la présente étude de la plupart des ouvrages précédents sur la structure et l'interprétation.
All Rights Reserved (C) Canadian University Music Society / Société de musique des universités canadiennes, 2012
Ce document est protégé par la loi sur le droit d'auteur. L’utilisation des services d'Érudit (y compris la reproduction) est assujettie à sa politique d'utilisation que vous pouvez consulter en ligne.

https://apropos.erudit.org/fr/usagers/politique-dutilisation/ 


\title{
PERFORMANCE STRATEGIES IN THREE RECORDINGS OF BACH'S INVENTION NO. 1 IN C MAJOR: A COMPARATIVE STUDY
}

\author{
Alan Dodson
}

For several decades, music psychologists have been studying performances and recordings in an effort to extrapolate basic principles underlying the differences between notation and the actual patterns of sound created by highly skilled performers. Anticipated in the increasingly detailed, rule-based treatises on performance that emerged in the eighteenth and nineteenth centuries, this line of scientific inquiry began in earnest at Carl E. Seashore's laboratory at the University of Iowa during the 1930s (see esp. Seashore 1936) and re-emerged, with the aid of computer technology, at a variety of European and North American research centres during the 1970s and 1980s. ${ }^{1}$ This ongoing empirical enterprise has helped to demystify the concept of musical expression. Contributors have understood, if only tacitly, that there will always be aspects of performance and reception that are so subtle, personal, and subjective as to be beyond the grasp of analysis. Nonetheless, a core premise of performance studies is that the expressive meaning of a given performance corresponds closely to the ways in which its rhythms and dynamics of actual performances and recordings (including those by highly accomplished musicians) diverge from the quantized values indicated in the score. Since the time of Seashore, then, performance expression has been equated in the empirical literature with deviation from the regular (Seashore 1947). Although this definition is highly reductive, it provides a plausible and practical starting point for the empirical investigation of a highly complex activity.

Since the late 1990s, the methods and models of empirical performance studies have entered the analytical toolkits of some historical musicologists and music theorists seeking new paradigms and concepts through which to describe the performance practices of various individuals and groups, relate those practices to aspects of musical structure, and interpret their significance at the level of cultural context, meaning, and value. ${ }^{2}$ As a music theorist, I am particularly interested in forging connections between performance analysis

1 For a comprehensive survey of this body of literature (up to ca. 2000), see Gabrielsson 1999, 2003. For an introduction to some of the most recent computational methods and models, see Widmer and Goebl 2004.

2 Musicologists associated with the Centre for the History and Analysis of Recorded Music (CHARM) and its successor, the Centre for Musical Performance as Creative Practice (CMPCP), have been at the vanguard of this multidisciplinary movement. Representative publications include Leech-Wilkinson 2009 and the CHARM special issue of the journal Musicae scientiae (Fall 2007). 
and the structure of the work in question (seen from the perspective of a given theoretical model). My research has focused mainly on accentuation and tempo rubato and their relationship to various aspects of rhythmic structure. ${ }^{3}$ The present case study is more exploratory. The aims are to highlight some of the most salient interpretive differences between selected recordings of a short piece (J. S. Bach's Invention No. 1 in C Major), to speculate on what these differences tell us about each performer's interpretation of the work's rhythmic structure (or, to put it another way, on how the recording might affect our own experience of that structure), and to seek parallels to these interpretations in the analytical discourse on the piece. More broadly, the study draws attention to the fact that even a seemingly simple and straightforward work can sometimes be conceptualized-and thus performed-in many different but equally viable ways, an idea that has often been eschewed in the literature on analysis and performance, and one that has been acknowledged only rarely in the empirical literature on performance. 4

Progress in performance-related research depends on two complementary activities: analysis and theorizing. Performance analysis is the close study of one or more specific performances or recordings. In practice, this typically involves looking for patterns in graphs of timing and dynamics that are based on measurements taken using computer software, so that highly variegated sets of performance data can be brought to the point of comprehensibility. Performance theory, on the other hand, aims to articulate general principles underlying many (or all) expert performances in a given style. Typically, a performance theory will take the form of a system of preference rules (see esp. Clarke 1988; Friberg, Bresin, and Sundberg 2006), and usually these rules map structural features onto performance practices. For instance, virtually all performance theories include some variant of the rule "Decelerate at the end of a phrase," in keeping with the observation that this performance practice is pervasive in the performance of Western art music. Performance analysis provides an empirical foundation for advances in performance theory, while performance theories offer a broader intellectual context and interpretive framework

The CHARM website is http://www.charm.rhul.ac.uk/index.html. The CMPCP website is http://www .cmpcp.ac.uk.

3 The aspects of rhythmic structure engaged in my publications include hypermeter (Dodson 2002), grouping structure (Dodson 2008), metrical dissonance (Dodson 2009), and phrase rhythm (Dodson 2011, 2012).

4 Most reviews of Wallace Berry's Musical Structure and Performance (1989) pointed out that writings in the "analysis and performance" genre are often extremely narrow and prescriptive, and that they tend to neglect recordings and devalue performers and their intuitions. (See especially Lester 1992.) Palmer (1989) was the first to examine the relationship between performers' phrase segmentations (as indicated through their own score annotations) and their actual expressive timing practices. Palmer's study not only provides further support for the (already widespread) view that performance expression is to a large extent rule-based, but also provides empirical evidence that in the case of ambiguous grouping structures, each performer's expressive timing practices tend to agree with his or her segmentation and contradict other possible segmentations. 
for performance analysis; as such, the two activities are interdependent. 5 The present study is principally an exercise in performance analysis.

Most research in performance analysis has concentrated on how performers respond to aspects of musical design at the level of the phrase or smaller (e.g., Repp 1998b). The present study aims also to describe patterns spanning an entire piece. These higher-level patterns can be understood, in a figurative sense at least, to represent overall performance strategies for a piece. One rationale for choosing J. S. Bach's Invention No. 1 in C Major for this study is that the piece is short enough that patterns of performance expression can be sought at the level of the entire piece without sacrificing attention to detail. As the methods employed for this study are very time-consuming, length necessarily becomes an important practical consideration. (The score is provided as an appendix.) Another important consideration is that this piece has been the subject of several published analyses, and this opens an occasion to consider possible resonances between performers' and music theorists' interpretations of the piece. Such an investigation was first recommended, as an alternative to prescriptive (theoretically driven) commentary on performance, in an important essay by Joel Lester (1995) and has been explored fruitfully in articles by other scholars (Urista 2007; Barolsky 2008; Dodson 2008). A final, more technical reason for choosing this piece is that its pitch range is relatively narrow and consistent, and its texture relatively thin and uniform, such that valid intensity measurements can be obtained. When the range is wide or the texture diverse, there can be a significant mismatch between intensity measurements and perceived dynamic levels (Lipscomb and Hodges 1996, 113).

\section{Performance Analysis Methods}

Empirical measurements form the basis of the illustrations used in this study, whose purpose is to represent basic performance practices-including the average tempo, tempo rubato, and dynamics-in a manner that can be surveyed easily, so that patterns can be found in the data. These figures can heighten our awareness of patterns of performance expression in each recording, and they can also compensate for the limits of human memory when comparing different recordings. Sometimes the patterns turn out to be inaudible, either because they represent fluctuations that fall below the just-noticeable differences for human perception or because they conflate different categories of performance expression (e.g., hesitations and tenutos sound different and serve different expressive purposes, but they are indistinguishable in an empirical analysis). For this reason, I always evaluate the audibility of the patterns and exclude specious findings before proceeding. It could be argued that this practice compromises the objectivity of the method. However, my reasons for using empirical methods have nothing to do with a quest for objectivity-a desirability that has, in any case, been called into question often enough (e.g., Lewin 1986;

5 A similar interplay of deductive and inductive reasoning occurs in the case of traditional, compositionally oriented music theory and analysis, as David Lewin pointed out more than forty years ago in his well-known exchange with Edward T. Cone (Lewin 1968). 
Higgins 1997). As noted above, I use empirical methods purely to sharpen my own (and, I hope, the reader's) perception of the performance expression in the recordings, and not to replace that perception.

To begin the analysis, each recording is saved on a computer's hard drive, after being converted to a WAV file (sampling rate: $44.1 \mathrm{kHz}$ ) using the program Audacity. ${ }^{6}$ Individual notes' onset times are then identified at the eighthnote level within each recording. This is accomplished using a two-stage process: first the onsets are identified automatically using the BeatRoot algorithm (Dixon 2001), 7 which is designed to seek periodicities of accentuation in the sound file at multiple levels. Corrections are then made using a well-established manual onset detection method (Clarke 2004; Repp 1998b). A spectrogram display and click track within the BeatRoot platform facilitate the corrections, and for even greater precision, I reduce the playback speed to 25 per cent. Once the onsets are identified, the inter-onset intervals (IOIs) (i.e., durations, timespans) at various levels of the metric hierarchy are calculated by simple subtraction. Another program, Sonic Visualiser, ${ }^{8}$ is then used to measure intensities (dynamic levels) in the piano and clavichord recordings. This program returns one intensity value per $10 \mathrm{~ms}$, so the initial data set is quite unwieldy. To make it more manageable, the peak intensity within $100 \mathrm{~ms}$ of each onset time is selected and the remaining values are discarded; this method returns one intensity value per eighth note. Both the IOI data and the intensity data are then plotted using a standard spreadsheet program. No attempt was made to analyze the intensities of the two voices independently. The balance of the parts ("voicing") is an important concern when Bach's Inventions are played on the piano, but there is not yet a well-established, ecologically valid technique for measuring the balance of parts in polyphonic acoustic instruments, so the intensity values discussed in this study are useful only for tracking accents and overall changes in dynamic level.

The performance analysis software mentioned above is more sensitive than the human ear, so just-noticeable differences (perceptual thresholds) for tempo and intensity change are helpful when surveying the data. These have been estimated at 5-10\% in the case of tempo (Halpern and Darwin 1982) and 0.5-2.0 dB in the case of intensity (Zwicker and Fastl 1999). Fluctuations falling short of these limits are in most cases imperceptible. A further complication is that the phrase-structural context has a bearing on perception; listeners are less sensitive to performance practices that are highly conventional in a given context (e.g., deceleration at the end of a phrase) than they are to performance practices that are unconventional (e.g., deceleration at an arbitrary point within the phrase, or acceleration at the end) (Repp 1998a, 1999a). To circumvent possible

6 Audacity for Linux, Macintosh, or Windows can be downloaded free of charge at http:// audacity.sourceforge.net.

7 BeatRoot runs on the Java platform and can be downloaded free of charge at http://www.eecs .qmul.ac.uk/ simond/beatroot/.

8 Sonic Visualiser for Linux, Macintosh, or Windows can be downloaded free of charge at http://www.sonicvisualiser.org. For a tutorial on Sonic Visualiser, see Cook and Leech-Wilkinson (2009). 
problems associated with these matters, the audibility of the findings is assessed continuously, and only the patterns that I can actually hear are retained for further study. Priority is given to patterns that are rather subtle, as these seem to hold the greatest intrinsic interest. In these cases, the performance analysis graphs can, I hope, serve as useful visual aids for the reader-listener, in addition to their initial role as discovery tools.

\section{Tempo And Style}

For this study, I chose three recordings of the C-Major Invention that struck me on first hearing as being highly distinctive in style, namely those by Harold Bauer (1921), Glenn Gould (1964), and Angela Hewitt (1994). 9 To put the selected recordings into a somewhat wider context, I analyzed a somewhat larger reference set consisting of recordings of the piece available through my university's music library and through the Stanford Archive of Recorded Sound (see discography). Because the analysis encompasses the entire piece and the method is time-consuming, I decided to limit the sample size at ten recordings, all by pianists. Let us begin by comparing Bauer's, Gould's, and Hewitt's recordings to one another on the basis of two values inferred from the full set of timing data for the ten recordings: the average tempo of each recording, which is the reciprocal of the average IOI at the tactus (quarter-note) level, and the degree of variance (standard deviation) among the tactus-level IOIs within each recording. In the empirical literature, these values are commonly taken to represent basic tempo (the tempo a listener would ascribe to the recording holistically) and the overall amount of tempo rubato (or "expressiveness") in the recording, respectively (Repp 1994, 1998b).

As table 1 shows, Hewitt's recording is the fastest in the set, at just over 85 bpm; Gould's is among the slowest, at 59 bpm; and Bauer's is on the fast side, at around $8 \mathrm{o} \mathrm{bpm}$. On a very general level, these values seem to suggest important differences in conception of the work's character among the recordings, especially between Gould's recording and the other two; Gould's recording might be described as having a rather serious affect, while Bauer's and (especially) Hewitt's seem lighter and more energetic. The first few measures of each recording should provide a sense of these elementary differences.

Table 1. Average Tempos

\begin{tabular}{|c|c|}
\hline Performer & Average tempo (bpm) \\
\hline Serkin & 52.1 \\
\hline Gould & 59.0 \\
\hline Bacchetti & 63.3 \\
\hline Tureck & 66.6 \\
\hline
\end{tabular}

9 I encourage the reader to listen to these recordings in full; Bauer's recording is available through the Naxos Music Library, and all three recordings can be purchased through iTunes and other online vendors. 
Table 1. (cont'd)

\begin{tabular}{lc}
\hline \multicolumn{1}{c}{ Performer } & Average tempo (bpm) \\
\hline Friskin & 78.5 \\
Balogh (1945) & 78.6 \\
Bauer & 79.5 \\
Borovsky & 80.0 \\
Balogh (1950) & 81.5 \\
Hewitt & $\mathbf{8 5 . 7}$ \\
\hline
\end{tabular}

It is well known that performers tend to use more rubato when the basic tempo is slow, and less rubato when the basic tempo is fast. ${ }^{10}$ In accordance with her fast tempo, Hewitt's level of tempo variance is indeed quite low, as table 2 shows. However, Bauer diverges from this trend; his recording is not only fast but also highly variable in tempo. A relatively high level of tempo variance is also a feature of Gould's recording, as table 2 shows, but Gould reserves virtually all of his tempo rubato for the final three measures of the piece. By excluding these final measures (table 3), it can be confirmed that the tempo variance in most of Gould's recording is extremely low-marginally lower, in fact, than in Hewitt's much faster recording. This situation shows that aural assessment can be helpful in the identification and revision of misleading empirical results.

Table 2. Amount of Rubato

\begin{tabular}{|c|c|}
\hline Performer & Standard deviation (ms) \\
\hline Tureck & 21.9 \\
\hline Balogh (1950) & 27.6 \\
\hline Hewitt & 31.8 \\
\hline Balogh (1945) & 37.1 \\
\hline Borovsky & 37.9 \\
\hline Serkin & 41.4 \\
\hline Friskin & 48.6 \\
\hline Gould & 48.8 \\
\hline Bacchetti & 89.8 \\
\hline Bauer & 124.8 \\
\hline
\end{tabular}

10 This axiom is found in numerous historical and contemporary writings on tempo rubato (Hudson 1994). 
Table 3. Amount of Rubato, Excluding Ending

\begin{tabular}{lc}
\hline \multicolumn{1}{c}{ Performer } & Standard deviation (ms) \\
\hline Tureck & 19.0 \\
Balogh (1950) & 22.2 \\
Borovsky & 24.2 \\
Gould & $\mathbf{2 8 . 6}$ \\
Balogh (1945) & 30.0 \\
Hewitt & $\mathbf{3 2 . 0}$ \\
Serkin & 38.6 \\
Friskin & 41.7 \\
Bacchetti & 44.2 \\
Bauer & $\mathbf{1 1 9 . 2}$ \\
\hline
\end{tabular}

A few general remarks on performance style might be offered at this stage, on the basis of these initial findings. The combination of a relatively fast basic tempo and extensive use of tempo rubato in Bauer's recording reflects its pre1945 provenance and evokes the late romantic era of pianism (often referred to as the "golden age of the piano"), while Hewitt's faster and stricter (and also technically more accurate) rendition suggests the influence of the modernist "early music movement" upon mainstream piano pedagogy, an influence that may have reached its peak during Hewitt's formative years. ${ }^{11}$ Gould's recording is more difficult to categorize stylistically, as it has a very steady tempo and clear sonority (orthodox "early music" practices) but also has a basic tempo slow enough that it seems to conform neither to romantic nor to "early music" norms. ${ }^{12}$

My preliminary account of the character of the three recordings has relied on general notions of performing style and has been framed by an empirical analysis of the basic tempo and tempo variance in all ten recordings. In what follows, musical structure (specifically, tonal structure and grouping structure) will become the principal frame of reference, and the analysis will encompass both timing and dynamics. The investigation will point to some similarities in how the three pianists seem to have conceptualized the work's structure, as well as some noteworthy differences in their manner of communicating that structure.

\section{Performance Strategies}

Two salient expressive tendencies can be discerned in Bauer's recording (figure 1). ${ }^{13}$ First, and most conspicuous, is his tendency to decelerate near the

11 For a full discussion of this shift in performing style, see Philip 1992, Hamilton 2008. Regarding changes in Bach performance practice at mid-century, see Fabian 2003.

12 This combination of romantic and modernist performance values is typical of Gould's style, as Bazzana (1997) demonstrates.

13 In graphs of expressive timing, the $\mathrm{Y}$ axis shows IOIs, not tempo values. Ascending slope indicates that the amount of time between beats is increasing (thus, deceleration), and descending 
ends of each phrase; specifically, Bauer takes a considerable amount of extra time immediately before the three cadence points, ${ }^{14}$ which fall at $\mathrm{mm} .71,151$, and 221..$^{15}$ (These excerpts are located at o:10-0:18, o:36-0:42, and o:57-1:10 in the recording.) Second, Bauer also tends to take extra time at the beginnings of phrases. ${ }^{16}$ The latter tendency is especially marked at the beginning of the third phrase (m. 151), where a contrasting episode is introduced (at o:42). He also takes extra time at the beginning of the second phrase (m. 71) but to a more subtle degree, and he restores the tempo more gradually in this case (o:18-o:24). One can even sense a slight hesitation on the first few notes of the opening phrase, followed by an acceleration (0:00-0:06). The last of these features is not reflected in figure 1, which begins at m. 12. ${ }^{17}$ Both of Bauer's timing tendencies-slow phrase endings and slow phrase beginnings-are highly conventional (see Clarke 1988); as we shall see, the other two recordings also exhibit the first tendency to some extent. In this sense, the contrast between Bauer's expressive timing practices and those in other recordings might be described as a difference of degree, rather than a difference in kind.

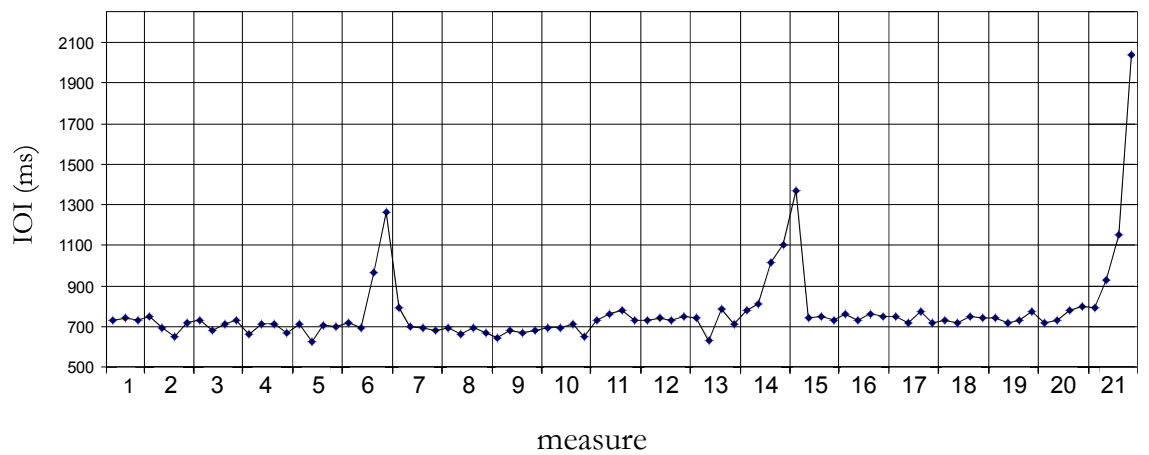

Figure 1. Bauer timing

Throughout the recording, Bauer's intensities correspond closely to directed harmonic motion within the phrase (figure 2). In the first phrase, he conveys a sort of intensity-wave that begins softly during the opening tonic prolongation (mm. 1-41, 0:00-0:09), builds during the modulation (mm. 42-62, 0:09-0:16), and then subsides into the cadence (0:16-0:18). The second phrase has a similar

slope indicates that the amount of time between beats is decreasing (thus, acceleration).

14 The cadence point is the inception of the final harmony of the phrase (e.g., the beginning of the tonic chord, in the case of a phrase that ends with an authentic cadence).

15 By "cadence point" I mean the moment when the phrase's final harmony begins. Throughout this article I use superscript notation to identify a beat within a measure (e.g., m. 71 means m. 7, beat 1).

16 The tendency for phrases' tempo profiles to resemble a parabola is discussed in Seashore (1936) and in many contemporary writings on expressive timing (see Gabrielsson 1999, 2003).

17 The downbeat of $\mathrm{m} .1$ is omitted from this graph because of the rest; in the absence of a note onset, an IOI value cannot be calculated. The final measure of the piece (m. 22) is also excluded from the graph. This is a convention in the empirical literature, and the rationale is that a further onset (after m. 22) would be needed in order to calculate an IOI. 
profile, except that the dynamic level does not diminish at the end (o:18-0:42). In the third phrase, the quiet opening lasts longer, and the crescendo continues well beyond the modulation and into the final cadence (o:42-1:10). Overall, each of the three intensity-waves becomes more teleological than the last, and this overarching pattern conveys a strong sense of large-scale unity and direction, notwithstanding the obvious discontinuities in tempo at the phrase boundaries.

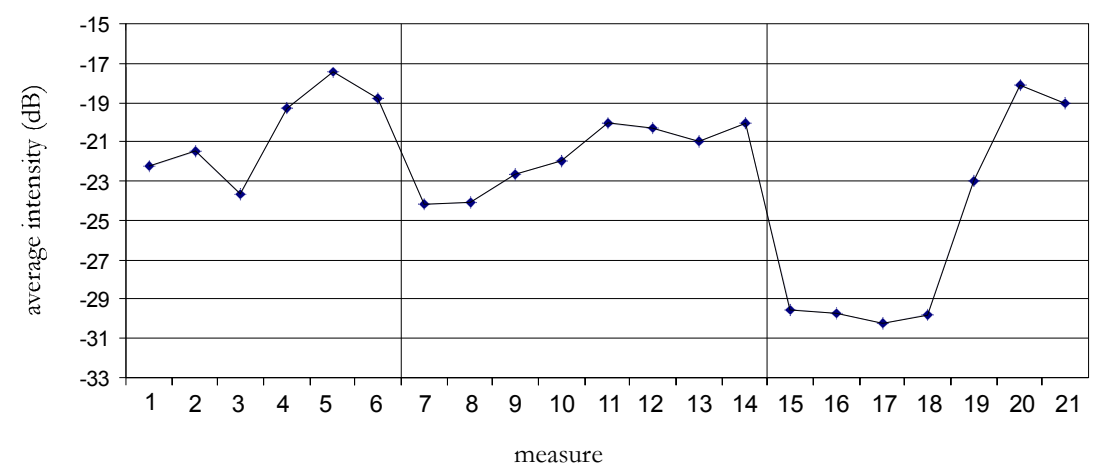

Figure 2. Bauer intensity

Gould also seems to use dynamics to communicate ideas about large-scale unity in the piece. As shown in figure 3 , a graph of the average intensity within each measure, he adds a crescendo in $\mathrm{mm}$. 6-11, followed by a diminuendo to $\mathrm{m}$. 15. This pattern is rather subtle and gradual, but it is audible (o:20-0:56). A clue to the possible meaning of this pattern is that the boundaries of the arch correspond almost exactly to the boundaries of the three phrases, while the peak coincides with the work's point of maximum tonal instability. In m. 11, there is a brief tonicization of II (D minor), the most remote tonal region in the piece, in the midst of a sequence that moves from $V$ ( $G$ major), the key of the first cadence (m. 7), to VI (A minor), the key of the second (m. 15). Indeed, throughout the performance, Gould adds a crescendo whenever the tonality becomes unstable, followed by a diminuendo as tonal stability returns; ${ }^{18}$ as such, figure 3 could almost be a map of tonal tension in the work.

A brief digression to a speculative performance theory from the late nineteenth century may provide further insight into the motivation behind Gould's performance expression in this case. In his Musical Expression, Mathis Lussy writes,

18 This occurs, for instance, in mm. 3-6 (modulation to G major, o:08-0:24) and 18-21 (tonicization of F major, 1:08-1:24). Related to this point, Gould begins to add extra ornamentation (beyond what is given in the Urtext) in $\mathrm{m} .7$ (0:24-0:28), and in $\mathrm{mm} .9-10$ (0:32-0:40) he adds a passing figure in thirty-second notes, which is probably derived from an early version of the piece in which the skips of a third were filled in with sixteenth-note triplets. These ornaments contribute further to the sense of intensification toward the midpoint of the piece; they are more than just a decorative melodic variation. 


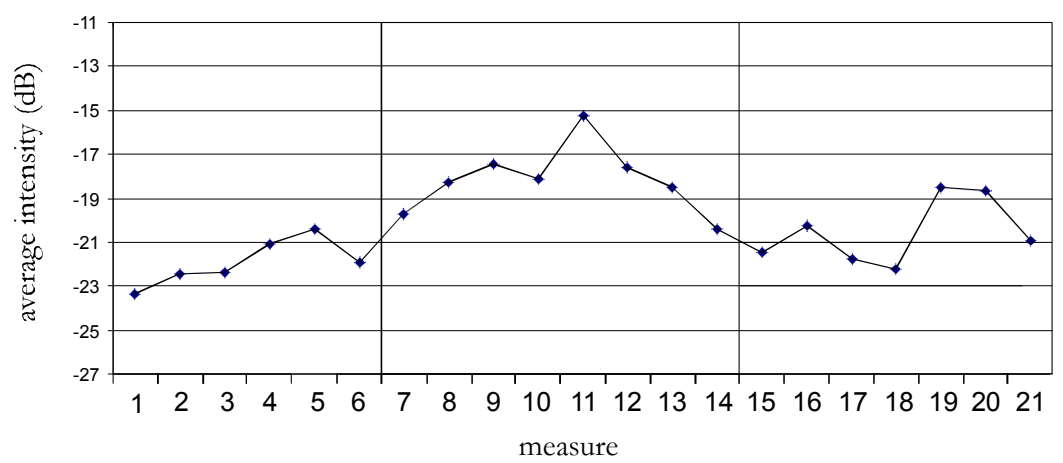

Figure 3. Gould intensity

Every time that a note or notes, foreign to the original key, present themselves ..., they have, so to speak, to be forced upon us, and consequently produce a startling impression. The first impulse is to regard these notes as false, but we soon feel that they are in accordance with the laws of tonality, key, time, and rhythm, and that they only lead to a new key, a new centre of attraction, or a new rhythmical design, and must be accepted. The artist will, therefore, manifest his impressions by more powerful tone and greater animation, followed by exhaustion and languor. (Lussy 1892, 126)

Here Lussy is suggesting that a temporary increase in dynamic level is called for whenever modulations or other departures from an established pattern occur. This hypothesis, which seems plausible in the abstract, is consistent with Gould's handling of dynamics, not only in this recording, but also in many others, for in his comprehensive study of Gould's recordings, Kevin Bazzana found that there is often a strong correlation between dynamics and tonal motion (Bazzana 1997, 210-11).

A graph of the average tactus-level IOI per measure in Gould's recording (figure 4) reflects the fact that, as noted above, Gould maintains a steady tempo through much of the performance but slows markedly toward the end. It also shows that Gould takes extra time at three distinct moments during the final four bars of the piece (1:12-1:30): in the middles of mm. 20 and 21, and the end of m. 21. The first of these points is the melodic climax; here a descending eighthnote figure follows an ascending sixteenth-note figure, and the descending figure's first note (C6) is the highest in the entire piece. ${ }^{19}$ The second place where Gould takes extra time, at the midpoint of m. 21, seems to be motivated by harmonic considerations. As in many of Bach's works, the closing section of this piece features lowered $\hat{\gamma}$ (B-flat), suggesting a tonicization of IV. This chromatic note appears for the last time immediately before the midpoint of $\mathrm{m}$. 21, and its diatonic counterpart (B-natural) appears very shortly thereafter. The third

19 Gould responds to the climax not through a dynamic accent (the high $\mathrm{C}$ is one of the quietest notes in the measure) but instead through a durational accent coupled with the most salient vocalization in the recording. Thus it could be described as an internalized or perhaps sublimated climax. 


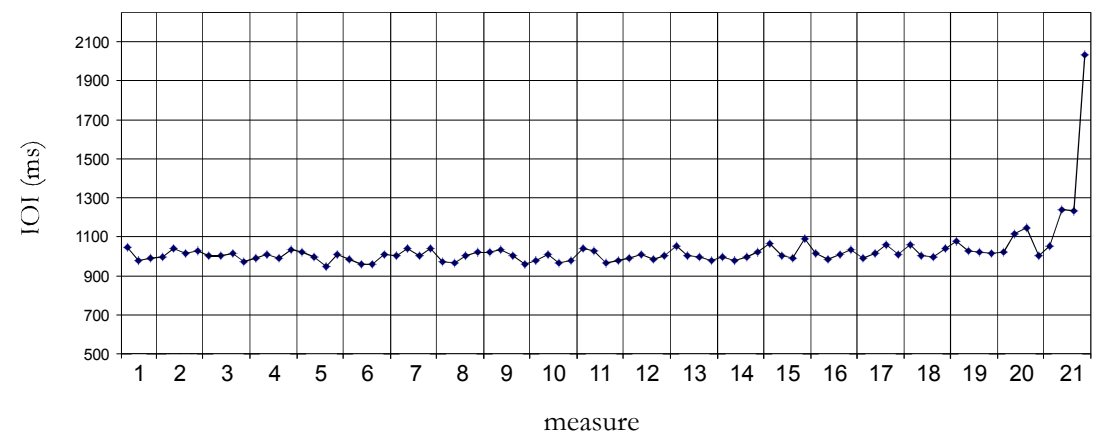

Figure 4. Gould timing

deceleration, at the end of $\mathrm{m} .21$, reflects the widespread convention of taking extra time at the end of a phrase, section, or piece.

In Hewitt's recording, a salient pattern of performance expression occurs toward the end of each phrase. In each case, the penultimate measure not only is the loudest measure in the phrase overall (figure 5) but also contains a crescendo that reaches its peak near the midpoint of the measure. It is noteworthy that Hewitt uses this pattern not only to set up the cadence points (found in $\mathrm{mm} .7,14$, and 21), but also for the $\mathrm{V}-\mathrm{I}$ motion in $\mathrm{D}$ minor in $\mathrm{mm}$. 10-11 (figure 6 , corresponding to $0: 12-0: 17,0: 23-0: 28,0: 34-0: 40$, and $0: 54-1: 03)$. In the context of the performance as a whole, then, the crescendo in $\mathrm{m}$. 10 suggests that Hewitt regards the V-I motion in D minor completed at the downbeat of $\mathrm{m}$. 11 as having greater structural weight than the other mid-phrase V-I progressions in the piece (e.g., those completed at the downbeats of mm. 3 and 9). For the first and third of these excerpts (i.e., in mm. 6 and 14), Hewitt also accelerates to the midpoint of the measure, thereby adding further excitement to the crescendo; she then takes extra time at the end of the measure to "place" the ensuing cadence point (figure 7). Overall, Hewitt's dynamics and (sometimes) timing practices reinforce the high state of harmonic tension associated with each phrase's cadential dominant, as well as the sense of momentary repose associated with the ensuing cadential tonic.

At the level of the entire piece, it seems that Hewitt (like Bauer and Gould) uses dynamics to communicate ideas about large-scale unity and direction (figure 5). More specifically, her variations in dynamic range convey a teleological interpretation of the invention's structure. The dynamic range is quite narrow (with a moderate dynamic level) in mm. 1-6 (o:00-0:17) but becomes more volatile in mm. 7-10 (o:17-0:28) and 11-14 (o:28-0:40). Then, in the final phrase, Hewitt sustains a soft dynamic level in mm. 15-18 (o:40-0:51) before introducing a grand crescendo to $\mathrm{m} .21$ (0:51-1:03). Within each phrase, there are many fluctuations of intensity that seem connected mainly to gestures and contrasts at sub-phrase levels. For instance, at the beginning of the piece Hewitt adds a subtle crescendo and diminuendo to highlight the contour in each group of seven sixteenth notes (0:00-0:02), a feature absent in the other two recordings. In this sense, Hewitt's performance strategy at the phrase level is 
quite different from that of Bauer, whose dynamics convey broader shapes (referred to above as "intensity-waves") at the phrase level. However, there is a palpable sense of mounting energy in Hewitt's recording, no less than in Bauer's, because each phrase is not only loudest near its end but also has a wider dynamic range than the previous phrase.

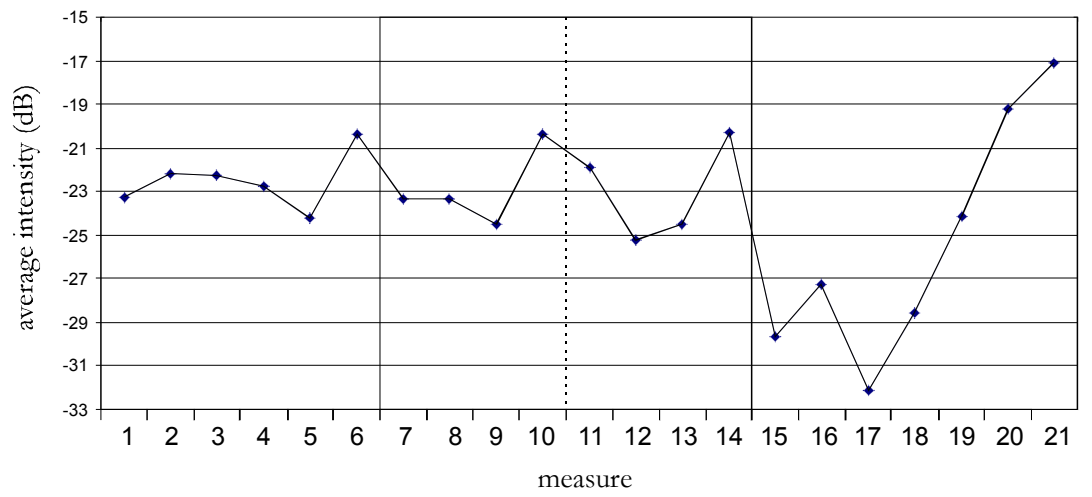

Figure 5. Hewitt intensity
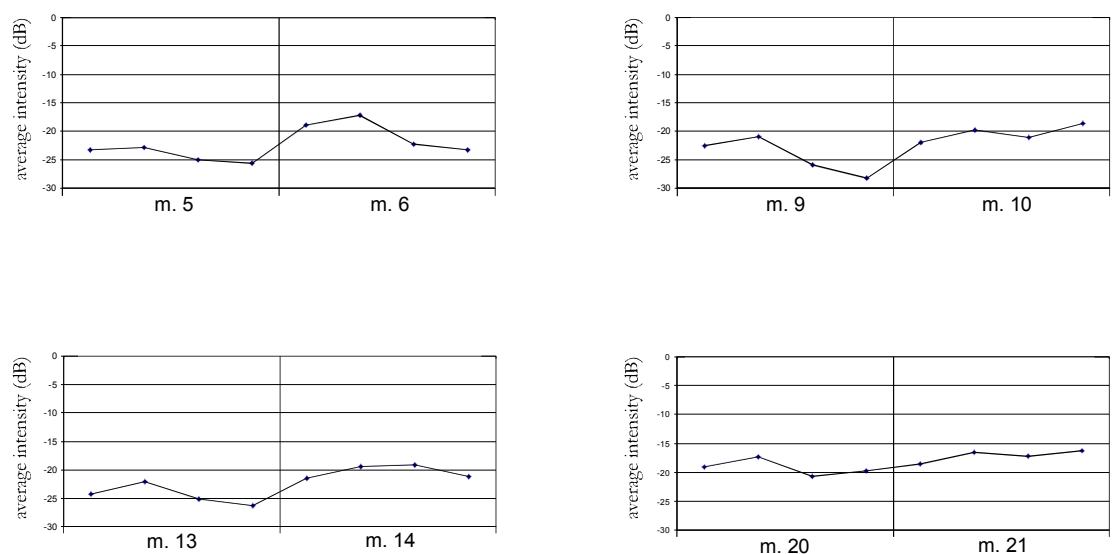

Figure 6. Hewitt intensity
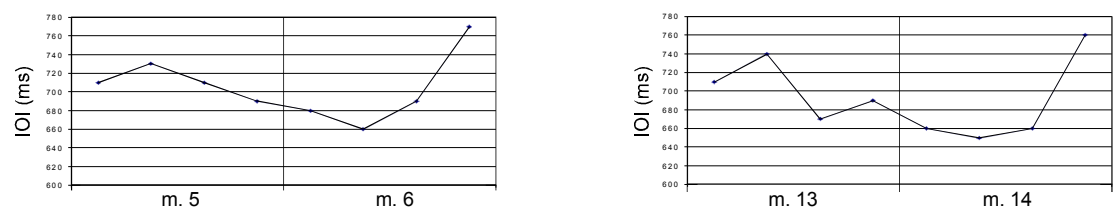

Figure 7. Hewitt timing 


\section{COMMONALITIES AND DifFERENCES}

The most remarkable commonality among the three recordings is that dynamics and large-scale form are closely related in all of them. In particular, Bauer's and Hewitt's recordings share a teleological dynamic profile overall, despite differences in performance strategy at the phrase level. This lends both recordings a clear sense of direction, shape, and coherence that transcends all of the expressive diversity at more local levels. In the case of Gould's recording, a connection to large-scale form is secured by the close parallel between dynamic levels and degrees of harmonic tension. As in the other two recordings, this performance strategy results in a unified overall dynamic profile-but now an arch, not a wedge.

There is also some agreement among the recordings (especially those by Bauer and Hewitt) regarding expressive timing and its relationship to phrase structure, especially at phrase endings. Bauer takes phrase rubato to the extreme; he decelerates very dramatically in the measure before each of the three clearest cadence points. Hewitt also employs phrase rubato throughout the piece, but her strategy is more restrained and localized than Bauer's. Also, as noted above, Hewitt seems to signal an impending cadence point, not only in the places where Bauer takes extra time, but also in $\mathrm{m}$. 10 (leading to the $\mathrm{D}$-minor chord at $\mathrm{m}$. 11), thereby suggesting a rather different interpretation of the work's phrase structure. Unlike Bauer and Hewitt, Gould makes minimal use of phrase rubato, except in the final measures of the piece. Perhaps he found it unnecessary to bring out cadences that confirm modulations adhering strongly to stylistic norms of the eighteenth century. As Bazzana explains,

Gould felt that rhythmic inflection was justified to the extent that tonal predictability was upset, that rhythmic inflections could act as a kind of analytical marker to the significance of tonal events. He said in a 1980 interview that "the further away you are from the conventional modulatory expectation ... the more reason there is at that point to consider that there should be a radical departure from the rhythmic, motoric norm that you have established" (Aikin 1980, 26-27). Discussing his performances of Mozart's sonata-allegro movements, he invoked a "theory of modulatory distance" as justification for relatively unyielding tempos: since he considered that the modulation from tonic to dominant, in the piano sonatas, was generally routine and unsurprising, he saw no need for rhythmic underscoring. (Bazzana 1997, 175)

Bach's inventions are almost as predictable as Mozart's sonatas in this respect, for in six of the eight major-key inventions, the first structural cadence is in (or, in one case, on) the dominant. ${ }^{20}$ Furthermore, the cadence points in mm. 7 and 15 punctuate conventional sentence structures (Ratz 1973b, 131), ${ }^{21}$ and perhaps Gould felt that most listeners would understand these structures

20 See Inventions No. 1 in C major, m. 7; No. 3 in D major, m. 12; No. 6 in E major, m. 20; No. 8 in F major, m. 12; No. 10 in G major, m. 14; No. 14 in B-flat major, m. 5.

${ }^{21}$ Many readers of this journal will be familiar with the work of Caplin 1998, which is strongly influenced (as the author himself points out) by Ratz's work, especially Ratz 1973a. 
intuitively, and that they would therefore expect the cadences at mm. 7 and 15, even in the absence of phrase rubato.

\section{Connections to the Analytical Discourse}

Among the many published analyses of Bach's Invention in C major, three Schenkerian analyses-those by Roy Travis (1976), Steve Larson (1983), and Howard Cinnamon (1983) - have especially close parallels to the overall performance strategies in the three recordings, as outlined above. ${ }^{22}$ All three analyses depict the piece as a 3-line, but they differ somewhat with regard to the pacing of the Ursatz. To Larson (example 1), the Urlinie descends to $\hat{2}$ early in the piece, at $\mathrm{m}$. 11, and the V that supports it arrives even earlier (in m. 5). Cinnamon (example 2) instead shows a long prolongation of the primary tone, lasting until m. 20, followed by a precipitous final descent closing at the downbeat of $\mathrm{m} .21 .{ }^{23}$ These analyses call to mind the performance strategies of Bauer and Gould: Larson and Bauer cast the cadence at m. 7 as structurally important, while Cinnamon and Gould downplay this cadence and convey a greater sense of stability and continuity until the final phrase of the piece. Travis's reading (example 3) is quite unorthodox and would probably be dismissed by some Schenkerians, ${ }^{24}$ but for our purposes it is significant because it corresponds to Hewitt's recording in one important respect: it places a strong emphasis on $\mathrm{m}$. 11. Travis's reading emphasizes the harmonic and linear roles of the D-minor chord in $\mathrm{m}$. 11, namely, prolonging the $\mathrm{V}$ that supports $\hat{2}$ and initiating the cadential progression in A minor. Thus, his reading conveys a sense of tension and continuity across $\mathrm{m}$. 11, despite the partial descent of the Urlinie at that point. Analogously, Hewitt's ritard draws attention to this moment, but it is less pronounced than her cadential ritards, so the flow of the music is not substantially disrupted.

What are we to make of these correspondences? These pianists are not known as exponents of Schenkerian analysis, and it seems highly unlikely that they conceptualize the piece precisely in the manner represented by the corresponding Schenkerian analysis. As well, the analysts make no mention of any performances or recordings that influenced them, and it seems likely that these sketches are informed by the analysts' own actual and imagined performances of the piece. Nonetheless, the parallels should not be very surprising,

22 In this section of the article I am assuming a basic familiarity with Schenkerian analysis. Readers unfamiliar with Schenker's approach may wish to consult the fifth chapter ("Tonal Structure") and appendix ("Introduction to Graphic Notation") in Cadwallader and Gagné (2007).

23 This sketch could be aligned more closely with the phrase structure by considering the $\mathrm{C}_{5}$ at the downbeat of $\mathrm{m} .21$ to be part of a passing figure supported by dominant harmony: $\mathrm{D}_{5}-\left(\mathrm{C}_{5}\right)-\mathrm{B}_{4}$. Indeed, this is how Schenker interprets m. 21 in his unpublished analysis of the piece (Schenker n.d.).

24 It is difficult to reconcile Travis's reading with the way in which Schenkerian interruption is normally understood. Interruption is associated above all with parallel periods, rounded binary forms, and sonata forms. Perhaps Travis is suggesting that the first phrase has an effect analogous to that of an antecedent phrase (the first branch of an interrupted structure) when taken out of context. His account of the resumption of the primary tone far is less convincing, because $\mathrm{m}$. 18 does not have an effect analogous to that of the beginning of a consequent phrase-or the beginning of any kind of phrase. 
because both performance practice and Schenkerian analysis are closely tied to aspects of phrase/grouping structure, including various aspects of continuity and discontinuity, directed motion, and closure. ${ }^{25}$ It is for this reason that, in my recent study on using alternative readings in Schenkerian analysis as a framework for comparing recordings (Dodson 2008), I suggest that grouping structure is likely to be the most fruitful area of common ground between Schenkerian analysis and performance expression.

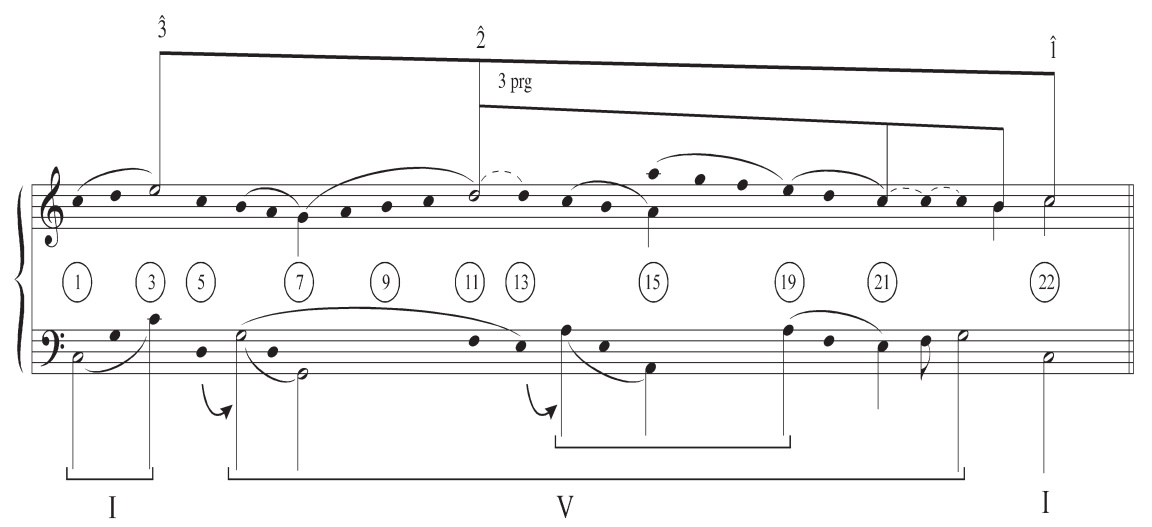

Example 1. Larson analysis

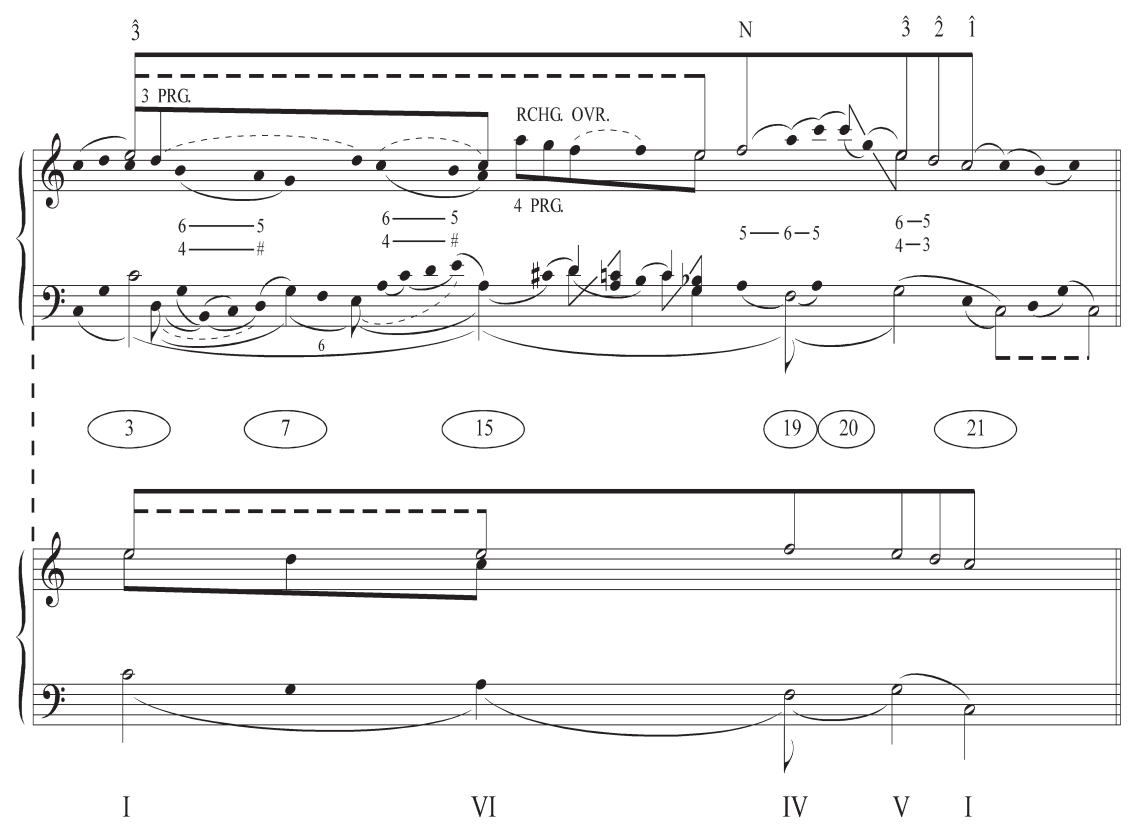

Example 2. Cinnamon analysis

25 The most comprehensive account of grouping structure is given in Lerdahl and Jackendoff (1983), 36-67. 


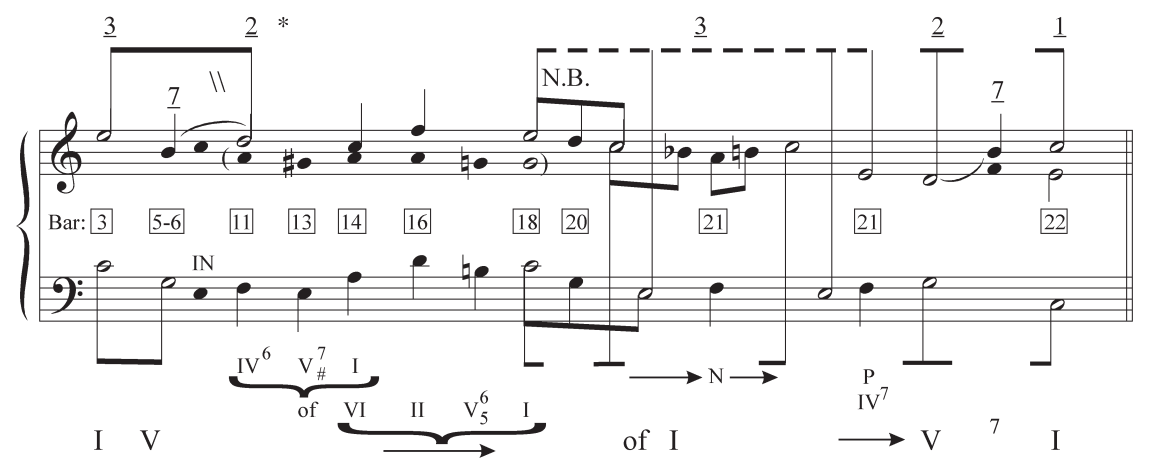

Example 3. Travis analysis

\section{Conclusion}

The methodology developed here is distinctive in that the listener/researcher's judgment plays a more prominent role than in traditional empirical research. In other words, the empiricist's "quest for objectivity" has been suspended here, or at least curtailed. Patterns in the data were singled out by simple inspection and not through the use of principal components analysis or other statistical transformations, ${ }^{26}$ and the audibility of these patterns was assessed through ordinary close listening-although well-established estimates of just-noticeable differences for intensity and timing were also considered. ${ }^{27}$ Finding a place not only for judgments about audibility but also for inferences about the aesthetic motivations behind the patterns has also been an important underlying concern. Some might criticize this as a recipe for over-interpretation, but it is motivated by a desire to develop an analytical method that not only resonates with my own musical experience, but also provides an opportunity to reflect upon, develop, enrich, and communicate aspects of that experience.

To date, most comparative studies on recordings of a given piece have made reference to a single account of the musical structure and have attributed differences among the recordings either to historical trends in performance style or to different weightings of generative principles that operate at the phrase level or smaller (e.g., Todd 1985; Repp 1998b; Widmer and Goebl 2004). ${ }^{28}$ In this sense, the empirical discourse on performance is not very different

26 Principal components analysis (PCA) is Repp's preferred method of finding patterns in performance data. (See, e.g., Repp 1998b, 1999b.) PCA is a statistical method that simplifies a data set by transforming a set of variables that are assumed to have some degree of intercorrelation (redundancy) into a smaller set of uncorrelated variables, the principal components (PCs). A PCA of timing in 100 recordings might yield three or four statistically significant PCs, and each recording would then be represented as a weighted sum of the PCs. The main advantages of this approach are its efficiency and elegance; its main disadvantage is that it is impossible to imagine what a PC sounds like, so the musical meaning of a single PC (let alone a weighted sum of PCs) is extremely difficult-or perhaps impossible-to grasp.

27 There is no guarantee, of course, that one listener's perceptions will be universally shared, so again I invite readers to listen to the recordings and judge for themselves whether or not the patterns I have pointed out are audible.

28 Palmer (1989) is an exception, as noted above. 
ideologically from the discourse on analysis and performance, in which ideas on how a work should be played are usually grounded in a single, privileged reading of the work's structure. By instead recognizing that the structure of a musical work is never fully determined-that different performers, listeners, and analysts may conceptualize a work in a variety of ways, even in the case of a piece that might seem, at first glance, to be simple and unambiguous-the approach outlined in this study offers the possibility of a more subtle and inclusive account of the complex relationship between musical structure (especially phrase/grouping structure) and performance expression. 
Appendix. J. S. BACH, Invention No. 1 in C Major, BWV 772
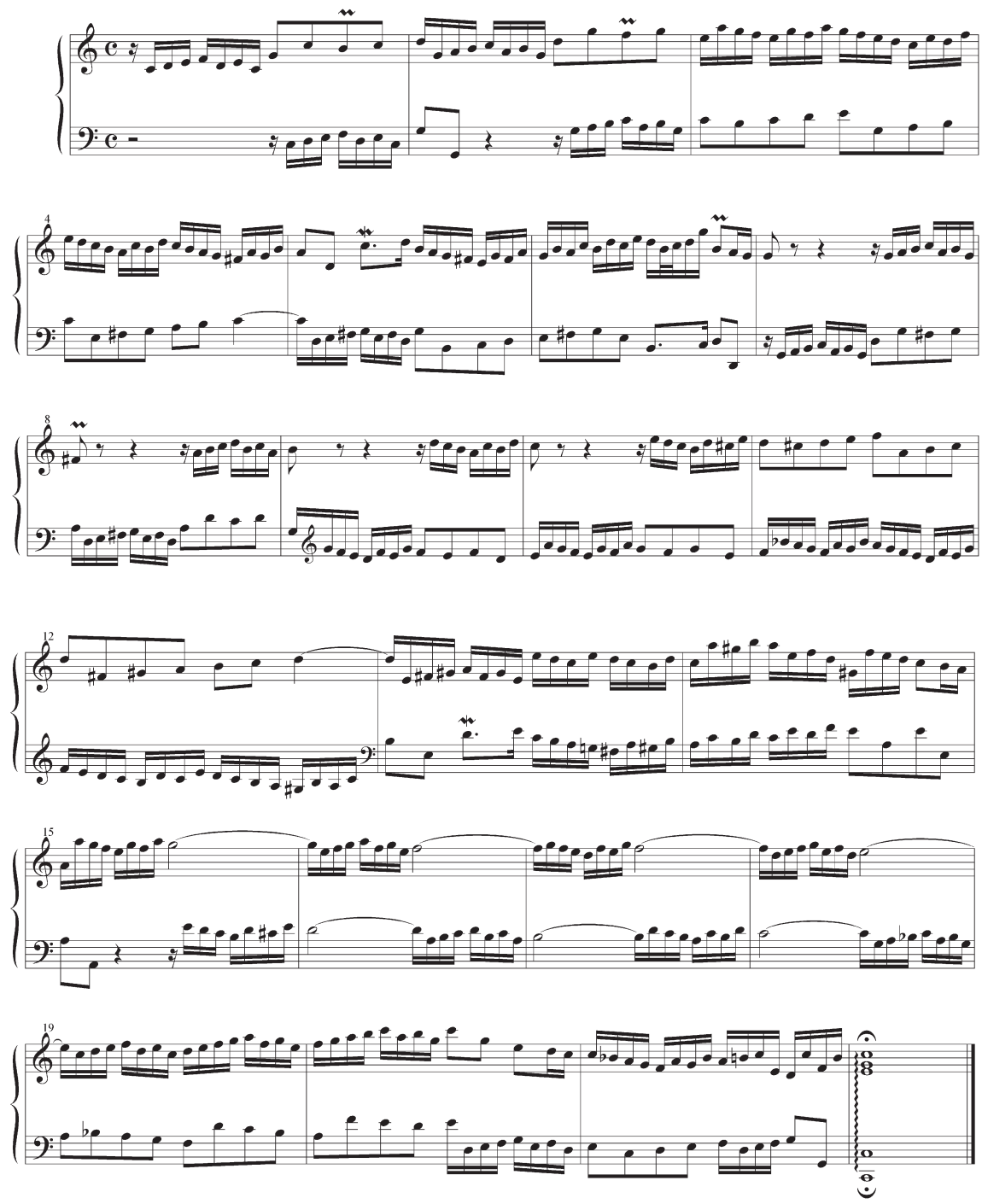


\section{REFERENCES}

Aikin, Jim. 1980. “Glenn Gould.” Contemporary Keyboard 6 (8): 24-28, 30-32, 36.

Barolsky, Daniel. 2008. "Embracing Imperfection in Benno Moiseiwitsch's Prelude to Chopin." Music Performance Research 2: 48-6o.

Bazzana, Kevin. 1997. Glenn Gould: The Performer in the Work. Oxford: Clarendon.

Cadwallader, Allen C., and David Gagné. 2007. Analysis of Tonal Music: A Schenkerian Approach. Oxford: Oxford University Press.

Caplin, William. 1998. Classical Form: A Theory of Formal Functions for the Instrumental Music of Haydn, Mozart, and Beethoven. New York: Oxford University Press.

Cinnamon, Howard. 1983. "Durational Reduction and Bach's C-Major Invention: An Alternative View." In Theory Only 7 (4): 25-35.

Clarke, Eric. 1988. “Generative Principles in Music Performance.” In Generative Processes in Music: The Psychology of Performance, Improvisation, and Composition, ed. John Sloboda, 1-26. Oxford: Clarendon.

- 2004. "Empirical Methods in the Study of Performance." In Empirical Musicology: Aims, Methods, Prospects, ed. Eric Clarke and Nicholas Cook, 77-102. Oxford: Oxford University Press.

Cook, Nicolas, and Daniel Leech-Wilkinson. 2009. A Musicologist's Guide to Sonic Visualiser. London: Centre for the History and Analysis of Recorded Music. http://www.charm.rhul.ac.uk/analysing/p9_1.html.

Dixon, Simon. 2001. "Automatic Extraction of Tempo and Beat from Expressive Performances." Journal of New Music Research 30: 39-58.

Dodson, Alan. 2002. "Performance and Hypermetric Transformation: An Extension of the Lerdahl-Jackendoff Theory." Music Theory Online 8 (1).

- 2008. "Performance, Grouping and Schenkerian Alternative Readings in Some Passages from Beethoven's 'Lebewohl' Sonata." Music Analysis 27: $107-34$.

- 2009. "Metrical Dissonance and Directed Motion in Paderewski's Recordings of Chopin's Mazurkas." Journal of Music Theory 53 (1): 57-94.

_. 2011. "Expressive Timing in Expanded Phrases: An Empirical Study on Recordings of Three Chopin Preludes." Music Performance Research 4: 2-29.

.2012. "Solutions to the 'Great Nineteenth-Century Rhythm Problem' in Horowitz's Recording of the Theme from Schumann's Kreisleriana, Op. 16, No. 2." Music Theory Online 18 (1).

Fabian, Dorottya. 2003. Bach Performance Practice, 1945-1975: A Comprehensive Review of Sound Recordings and Literature. Aldershot: Ashgate.

Friberg, Anders, Roberto Bresin, and Johan Sundberg. 2006. "Overview of the KTH Rule System for Musical Performance." Advances in Cognitive Psychology 2 (2-3): 145-61.

Gabrielsson, Alf. 1999. “The Performance of Music.” In The Psychology of Music, 2nd ed., ed. Diana Deutsch, 501-602. San Diego: Academic. 
- 2003. "Music Performance Research at the Millennium." Psychology of Music 31: 221-72.

Halpern, A. R., and C. I. Darwin. 1982. "Duration Discrimination in a Series of Rhythmic Events.” Perception and Psychophysics 31: 86-89.

Hamilton, Kenneth. 2008. After the Golden Age: Romantic Pianism and Modern Performance. Oxford: Oxford University Press.

Higgins, Kathleen Marie. 1997. "Musical Idiosyncrasy and Perspectival Listening." In Music and Meaning, ed. Jenefer Robinson, 83-102. Ithaca: Cornell University Press.

Hudson, Richard. 1994. Stolen Time: The History of Tempo Rubato. Oxford: Clarendon.

Larson, Steve. 1983. "On Analysis and Performance: The Contribution of Durational Reduction to the Performance of J. S. Bach's Two-Part Invention in C Major." In Theory Only 7 (1): 31-45.

Leech-Wilkinson, Daniel. 2009. The Changing Sound of Music: Approaches to Studying Recorded Musical Performances. London: Centre for the History and Analysis of Recorded Music. http://www.charm.rhul.ac.uk/studies/ chapters/intro.html.

Lerdahl, Fred, and Ray Jackendoff. 1983. A Generative Theory of Tonal Music. Cambridge, MA: MIT Press.

Lester, Joel. 1992. Review of Musical Structure and Performance, by Wallace Berry. Music Theory Spectrum 14 (1): 75-81.

_. 1995. "Performance and Analysis: Interaction and Interpretation." In The Practice of Performance: Studies in Musical Interpretation, ed. John Rink, 197-216. Cambridge: Cambridge University Press.

Lewin, David. 1968. "Behind the Beyond: A Response to Edward T. Cone." Perspectives of New Music 7: 59-69.

-1986, "Music Theory, Phenomenology, and Modes of Perception." Music Perception 3: 327-92.

Lipscomb, Scott D., and Donald A. Hodges. 1996. "Hearing and Music Perception." In Handbook of Music Psychology, ed. Donald A. Hodges, 83-132. San Antonio, TX: IMR.

Lussy, M. 1892. Musical Expression: Accents, Nuances, and Tempo, in Vocal and Instrumental Music, trans. M. E. von Glehn. London: Novello.

Myers, Kurtz. 1978. Index to Record Reviews: Based on Material Originally Published in Notes, the Quarterly Journal of the Music Library Association, between 1949 and 1977. Boston: G. K. Hall.

Palmer, Caroline. 1989. "Mapping Musical Thought to Musical Performance." Journal of Experimental Psychology: Human Perception and Performance 15 (2): 331-46.

Philip, Robert. 1992. Early Recordings and Musical Style: Changing Tastes in Instrumental Performance, 1900-1950. Cambridge: Cambridge University Press.

Ratz, Erwin. 1973a. Einführung in die musikalischen Formenlehre: Über Formprinzipien in den Inventionen und Fugen J. S. Bachs und ihre Bedeutung für die Kompositions-technik Beethovens. $3 \mathrm{~d}$ ed., enlarged. Vienna: Universal. 
Ratz, Erwin. 1973b. “The Formal Principles," trans. Eugene Hartzell. In J. S. Bach, Inventionen und Sinfonien (2- und 3-stimmige Inventionen) (BWV 772-801), ed. Erwin Ratz and Karl Heinz Füssl, 131-36. Vienna: Wiener Urtext.

Repp, Bruno H. 1994. "On Determining the Basic Tempo of an Expressive Music Performance." Psychology of Music 22: 157-67.

_.1998a. "The Detectability of Local Deviations from a Typical Expressive Timing Pattern.” Music Perception 15: 265-90.

_. 1998b. "A Microcosm of Musical Expression: I. Quantitative Analysis of Timing Microstructure in the Initial Measures of Chopin's Etude in E major." Journal of the Acoustical Society of America 104: 1085-1100.

_ 1999a. "Detecting Deviations from Metronomic Timing in Music: Effects of Perceptual Structure on the Mental Timekeeper." Perception and Psychophysics 61: 529-48.

_.1999b. "A Microcosm of Musical Expression: II. Quantitative Analysis of Pianists' Dynamics in the Initial Measures of Chopin's Etude in E Major." Journal of the Acoustical Society of America 105: 1972-88.

Schenker, Heinrich. n.d. Unpublished analytical sketch of J. S. Bach's Invention No. 1 in C Major, item 8, file 68, Oster Collection, New York Public Library.

Seashore, Carl E., ed. 1936. Objective Analysis of Musical Performance. Iowa City: University [of Iowa] Press.

Seashore, Carl E. 1947. "Principles of Deviation from the Regular." In In Search of Beauty in Music: A Scientific Report, 71-81. New York: Ronald.

Todd, Neil P. McAngus. 1985. "A Model of Expressive Timing in Tonal Music." Music Perception 3: 33-58.

Travis, Roy. 1976. "J. S. Bach, Invention No. 1 in C Major: Reduction and Graph." In Theory Only 2 (7): 3-7.

Urista, Diane. 2007. “Chopin’s Prelude in C Major Revisited: Integrating Sound and Symbol." Music Theory Online 13 (1).

Widmer, Gerhard, and Werner Goebl. 2004. "Computational Models of Expressive Music Performance: The State of the Art." Journal of New Music Research 33: 203-16.

Zwicker, Eberhard, and Hugo Fastl. 1999. "Just-Noticeable Sound Changes." In Psychoacoustics: Facts and Models, 2d ed., 175-201. Berlin: Springer-Verlag.

\section{Discography}

For the sake of simplicity, only one date is provided per recording. Where known, the date of recording is used. In cases where no date is printed on the disc or disc jacket, an estimated date of issue is provided in brackets, based mainly on the date of the earliest North American record review (as cited in Myers 1978).

Bacchetti, Andrea. Rec. 2008. Dynamic CDS629. Compact disc.

Balogh, Erno. [1945]. Asch set 102. 78 rpm record.

Balogh, Erno. [1950]. Lyrichord 1. LP record.

Bauer, Harold. Rec. 1921. Nimbus Records NI 8808. Compact disc reissue. Borovsky, Alexander. [1958]. Vox PL 10550. LP record. 
Friskin, James. [1954]. Bach Guild BG-545. LP record.

Gould, Glenn. Rec. 1964. Sony Classics 82876-78766-2. Compact disc reissue. Hewitt, Angela. Rec. 1994. Hyperion CDA66746. Compact disc.

Serkin, Peter. Rec. 1995. RCA Victor Red Seal 09026-68594-2. Compact disc. Tureck, Rosalyn. Rec. 1979. Sony Classical SB2K 63231 63232. Compact disc reissue.

\begin{abstract}
After a brief introduction to the field of empirical performance studies and its goals and methods, recordings of the titular work by pianists Harold Bauer, Glenn Gould, and Angela Hewitt are discussed. It is suggested that these recordings demonstrate three distinct performance strategies for the piece: Bauer highlights the boundaries of each phrase and projects a teleological design within each phrase and at the level of the entire piece; Gould conveys an arch-shaped design tied to harmonic tension; and Hewitt draws attention not only to the three structural cadences (mm. 7, 15, and 22) but also to a subsidiary V-I motion at $\mathrm{m}$. 11, thereby hinting that it might have structural importance. Parallels between these performance strategies and analyses by Howard Cinnamon, Steve Larson, and Roy Travis are briefly considered. The emphasis on multiplicity in this study distinguishes it from most earlier scholarship on structure and performance.
\end{abstract}

\title{
RÉSUMÉ
}

Après une brève introduction au domaine des études d'interprétation empirique et à ses objectifs, l'auteur traite d'enregistrements de l'œuvre mentionnée dans le titre par les pianistes Harold Bauer, Glenn Gould et Angela Hewitt. Il soutient que ces enregistrements témoignent de trois stratégies d'interprétation distinctes de l'œuvre : Bauer fait ressortir les limites de chaque phrase et projette une conception téléologique au sein de celle-ci et à l'échelle de l'œuvre dans son ensemble, Gould adopte une conception en forme d'arche liée à la tension harmonique, tandis que Hewitt attire l'attention non seulement sur les trois cadences structurelles (aux $7^{\mathrm{e}}, 15^{\mathrm{e}}$ et $22^{\mathrm{e}}$ measure), mais aussi à un mouvement subsidiaire $\mathrm{V}-\mathrm{I}$ à la 11 measure, faisant ainsi allusion à son importance structurelle possible. L'auteur établit brièvement des parallèles entre ces stratégies d'interprétation et des analyses de Howard Cinnamon, de Steve Larson et de Roy Travis. L'accent sur la multiplicité distingue la présente étude de la plupart des ouvrages précédents sur la structure et l'interprétation. 